\title{
Top Five Causes of Neck Mass in Chattogram
}

\author{
Ziaul Answar Chowdhury ${ }^{1}$ \\ M. Jalal Uddin ${ }^{*}$ \\ Ashfaq Ahmad ${ }^{1}$ \\ Abbas Uddin ${ }^{3}$ \\ Nurul Karim Chowdhury ${ }^{4}$ \\ H.S. Mubarak Hossain ${ }^{4}$ \\ Mahbubul Alam Chowdhury ${ }^{5}$ \\ Dhananjoy Majumder ${ }^{6}$
}

'Department of ENT

250 bedded Chattogram General Hospital

Chattogram, Bangladesh.

${ }^{2}$ Department of Community Medicine Chattogram Maa-O-Shishu Hospital Medical College Chattogram, Bangladesh.

${ }^{3}$ Department of ENT

BGC Trust Medical College

Chattogram, Bangladesh.

${ }^{4}$ Department of ENT

Chittagong Medical College

Chattogram, Bangladesh.

${ }^{5}$ Department of ENT

Institute of Applied Health Sciences (IAHS)

Chattogram, Bangladesh.

${ }^{6}$ Department of Otolaryngology \& Head Neck Surgery Southern Medical College

Chattogram, Bangladesh.

\begin{abstract}
Background: Identifying top problems in any discipline is very important for diagnosis and effective management. Unfortunately there is a knowledge gap in Chattogram, Bangladesh. To fill up the gap we have conducted the study.
\end{abstract}

Materials and methods : It was a retrospective study based on hospital records of Chattogram General Hospital from January 2017 to December 2017. All (104) cases with neck mass were included. Age, sex, clinical diagnosis, histo-pathological diagnosis and management were noted. Data were managed manually.

Results: Total 104 cases were studied among the cases 65\% were female and 35\% were male. $91 \%$ cases were of $10-50$ years age group. Highest cases 33\% were found in 20-30 years age group. According to Histo-pathological report $25 \%$ cases were Tubercular lymphadenopathy, Nonspecific lymphadenopathy were $17 \%$ and Multi-nodular goiter were 15\%. Results were contrasted with previous studies.

Conclusion: Top 05 causes of neck mass in Chattogram have been unveiled. Tuberculosis is still number one problem. So, TB control program should be evaluated further to find out causes of high TB cases in this region.

Key words: Causes; Neck mass; Chattogram.

\section{INTRODUCTION}

Neck masses are common in general practice. These are usually painless and slow growing. Some may be present at birth and some may develop later ${ }^{1}$. Clinically neck masses can be divided into ${ }^{2}$ :

A. Midline Masses

Enlarged Lymph node, Dermoid, Ludwig angina, Thyroglossal cyst

Aberrant thyroid, Thyroid Isthmus Tumor, Laryngeal Malignancy etc.

B. Lateral Aspect Masses

Inflammatory Lymph Nodes, Metastatic Lymph nodes

Neoplastic Lymph Nodes, Cystic hygroma, Sub clavian aneurysm

Salivary gland inflammation, Salivary gland tumor

Branchial cyst, Pharyngeal pouch, Swelling of thyroid lobe.

Neck Masses Can be Classified According to Onset of the Problem ${ }^{3}$ :

A. Acute (Days to weeks)

Tubercular lymphadenopathy

Non Specific lymphadenopathy (Bacterial, Viral)

Acute sialadenitis, Hematoma etc.

B. Sub Acute (Weeks to months)

Squamus cell carcinoma of tongue, Carcinoma Larynx

Lymphoma, Metastasis, Salivary gland tumor. 


\section{Chronic (Months to years)}

Thyroid mass (Benign or malignant) Lipoma

Laryngocele, Branchial cyst, Thyroglossal cyst etc.

The primary concern of neck mass is to exclude malignancy. Malignancies are common usually over 40 years smoker group. History and physical examination often diagnose neck mass. In some cases ultrasonography, CT Scan, FNAC may be needed ${ }^{4}$. In our context excision and histopathology is the most costeffective option for diagnosis and management of neck masses. CT scan helps particularly for malignancy to see its extension. FNAC also helpful but it is less sensitive than histopathology.

\section{MATERIALS AND METHODS}

It is a retrospective observational study. The study was conducted at Chattogram General Hospital with due permission from the authority. Hospital records from January 2017 to December 2017 were studied. Sample size 104. Available data related to age, sex, clinical diagnosis, management and histo-pathological diagnosis were noted. Data were managed manually. Results were compared and contrasted with previous similar studies.

\section{RESULTS}

Total 104 cases were studied. Among them $65 \%$ were female and $35 \%$ were male. Maximum case holding age group was 20 30 years. It was $33 \%$ and is followed by $10-20$ years $23 \%, 30$ 40 Years $21 \%$ and $40-50$ Years $14 \%$ respectively. Histopathologically TB Lymphadenopathy was the top ranking $26(25 \%)$ followed by Non specific Lymphadenitis 18(17\%) Multinodular goiter $16(15 \%)$ Thyroid cancer $7 \%$ respectively. Metastatic carcinoma and lymphoma hold $5^{\text {th }}$ position jointly i.e $5 \%$. Others were lipoma $4 \%$, pleomorphic adenoma $4 \%$, Benign mesenchymal leision $4 \%$, bronchial cyst 3\%, neurofibroma 3\%, thyroglosal cyst $3 \%$, hemangioma $3 \%$, Sialadenitis $2 \%$.

Table I : Age group of the cases.

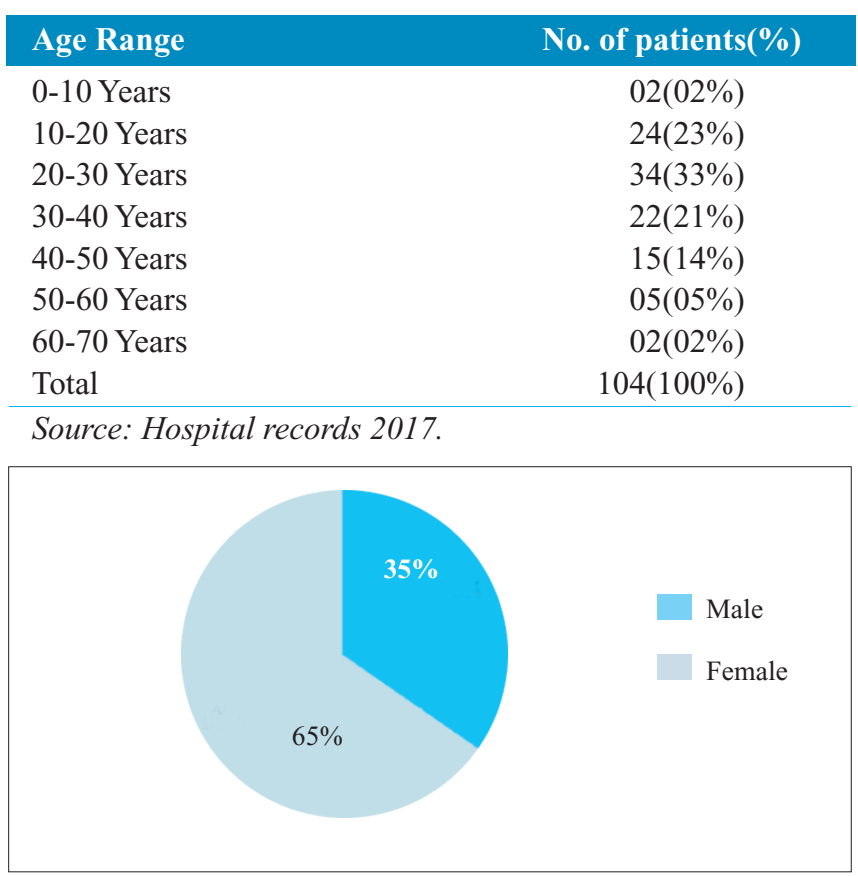

Figure 1 : Cases according to sex.
Table II : Histopathological diagnosis of neck mass.

$\begin{array}{lc}\text { Diagnosis } & \text { No.of cases (\%) } \\ \text { TB Lymphadenopathy } & 26(25 \%) \\ \text { Non specific lymphadenitis } & 18(17 \%) \\ \text { Multinodular goiter } & 16(15 \%) \\ \text { Thyroid Cancer } & 07(07 \%) \\ \text { Metastatic carcinoma } & 05(05 \%) \\ \text { Lymphoma } & 05(05 \%)\end{array}$

Source: Hospital records 2017.

\section{DISCUSSION}

In this study no malignant case was found in 0-20 years age group. All thyroid malignancies were found within 20-40 years age group. All metastatic cases and lymphoma were found in 40-60 years age group. Tubercular lymphadenopathy was found in all age groups. Non specific lymphadenitis was also found in all age groups. According to Mahmudul Hoq et al TB lymphadenopathy and Multinodular goiter 24\% respectively. Thyroid carcinoma, metastatic carcinoma and lymphoma $10 \%$ respectively ${ }^{5}$. They also noted about, non specific inflammatory condition, benign and congenital lesions. There is no significant difference at first position in both the studies $(\mathrm{p}<0.03)$ but second position differs significantly i.e Non specific lymphadenitis and multinodular goiter. Malignancies are available in both the studies but quantitative difference has been observed. The difference may be due to regional variation. In western countries TB lymphadenopathy is significantly less than that of Bangladesh. It arises question about effectivity of anti TB program in Bangladesh.

\section{CONCLUSION}

Top five causes of neck mass in Chattogram region have been identified.Very high rate of TB lymphadenopathy needs further evaluation of anti TB program in Bangladesh.

\section{DISCLOSURE}

All the authors declared no competing interest. 
REFERENCES

1. De SK. Fundamentals of ear nose throat and head neck surgery. $9^{\text {th }}$ edition. Kolkata : The new Book stall. 2010.

2. $\quad$ Dhingra PL, Dhingra S. Diseases of ear nose \& throat. $6^{\text {th }}$ edi. New Delhi: Elsevier. 2014.

3. Causes of neck Mass in adults. Family practice note book.Available at : (https://fpnotebook.com/ENT/Hemeone/CsofnckMsInAdlts.htm).

4. Haynes J, Arnold KR, Oskin CA, Chandra S. Evaluation of neck masses in adults . American family physician. 2015; 91(10):698-706.

5. Huq M, Ali M, Hoque S,Alam K, Satter M and Tarafder K. Evaluation of neck swelling by cytological and histopathological examination. Bangladesh journal of otorhinolaryngology. $2012 ; 18(1): 23-29$ 